\title{
Ulises después de Homero ${ }^{1}$
}

\author{
Claudio Magris
}

\section{$\&$}

"Nada -escribe Paul Valéry- demuestra más seguramente la potencia de un creador como la infidelidad o la insubordinación de su criatura. Cuanto más él la ha hecho viviente, tanto más la ha hecho libre. Hasta la rebelión de ella exalta a su autor: Dios lo sabe... Estos personajes... los ha generado de tal manera que pueden volverse, por medio suyo, instrumentos del espíritu universal: ellos van del otro lado de lo que fueron en su obra... los ha consagrado para siempre a la expresión de algunos extremos de lo humano y de lo inhumano; y, por tanto, desvinculado de cada aventura particular". Valéry escribe estas páginas en la introducción a Mon Faust, refiriéndose a aquellas figuras que reaparecen continuamente en la literatura de todo tiempo y país, como Antígona, Fausto, Don Juan, Ulises.

El significado de este último -o mejor de la Odisea, de toda odisea- está ligado al regreso y a la gran pregunta de si el viaje de la vida permite o no el regreso. “iAdónde os dirigís?" pregunta alguien a los viandantes en el Heinrich von Ofterdingen (1798 -1801), la gran novela de Novalis. "Siempre hacia casa", es la respuesta. Cada odisea plantea la interrogante sobre la posibilidad de atravesar el mundo haciendo de ello real experiencia y formando así la propia personalidad. La pregunta de si Ulises -especialmente el moderno- al final regresa a casa consolidado, no obstante las más trágicas y absurdas peripecias, en la propia identidad y habiendo encontrado o confirmado un sentido de la existencia, o si él descubre solamente la im-

1 Discurso ofrecido por Claudio Magris al recibir el Doctorado Honoris Causa otorgado por la Universidad Nacional Mayor de San Marcos el 11 de diciembre del 2009. 
posibilidad de formarse, si él se pierde por el camino a sí mismo, si pierde el significado de su vida, disgregándose en lugar de construirse en su camino, siempre está allí. Si él regresa a Itaca o si vuelve para partir nuevamente y perderse definitivamente.

En la visión clásica, el sujeto, aunque perdido en el vértigo de las cosas, termina por encontrarse a sí mismo en la confrontación con este vértigo; atravesando el mundo él descubre la propia verdad, que al inicio en él es sólo potencial y latente y que él traduce en realidad a través de la confrontación con el mundo, como el héroe de Novalis. En el Prinzip Haffnung (Principia Esperanza, 1954 59 ) Bloch dice que la Heimat, la patria, la casa natal que cada uno en su nostalgia cree ver en la infancia, se encuentra en cambio al final del viaje. Este último es circular: se parte de casa, se atraviesa el mundo y se regresa a casa, aunque es muy diferente de aquella casa abandonada, porque ha adquirido significado gracias a la partida, a la escisión originaria. Ulises regresa a Itaca, pero Itaca no sería tal si él no la hubiera abandonado para ir a la guerra de Troya, si él no hubiera roto los vínculos viscerales e inmediatos a ella para poderla reencontrar con mayor autenticidad. La condición del hombre, ha escrito Kart Rahner, gran teólogo en camino, es el status viataris, condición existencial del viajero que termina sólo con la muerte.

En el Bildungsroman, la novela de formación, se plantea un problema central de la modernidad o sea, se pregunta si y cómo el individuo puede realizar o no la propia personalidad insertándose en el engranaje cada vez más complejo y "prosaico" de la sociedad. Este es casi siempre - desde el Wilhelm Meister (1795-96) de Goethe hasta el Heinrich van Ofterdingen de Novalis - también un desafío, una peregrinación, un viaje. Pero pronto algo, en la relación entre la singularidad y la totalidad que rodea al personaje, se daña; en la máquina de la sociedad moderna el viajar se vuelve también rehuir, una violenta fractura de límites y vínculos. El viaje descubre no sólo la precariedad del mundo, sino también la del viajero, la labilidad del yo individual, que comienza - como intuirá con despiadada claridad Nietzsche - a disgregar la propia identidad y la propia unidad, 
a convertirse en otro hombre, "más allá del hombre”, según el significado más auténtico del término Übermensch, que no indica un superhombre, un individuo tradicional más dotado que los demás, sino una nueva etapa antropológica, más allá de la individualidad clásica (Gianni Vattimo). La odisea es sobre todo transformación y no sólo la de los compañeros de Ulises transformados en puercos por Circe, sino del hombre mismo en si.

Ulises, el Ulises de la modernidad y aún más de nuestra contemporaneidad, se hace verdaderamente Nadie, figura de ese nadie contemporáneo que es el individuo. El viaje se vuelve entonces un camino sin regreso, al descubrimiento que no existe, no puede y no debe haber regreso. No el feliz atraque en Ítaca, sino la partida hacia el loco vuelo del Ulises dantesco. El viaje circular, tradicional, clásico, edípico, conservador de Joyce, cuyo Ulises regresa a casa, es sustituido paulatinamente por el viaje rectilíneo, nietzscheano de los personajes de Musil; un viaje que continúa siempre adelante, hacia un malvado infinito, como una recta que avanza tambaleándose en la nada. Ítaca y más allá, como dice el título de un libro que he escrito; las dos modalidades existenciales, trascendentales del viajar. En la segunda el sujeto, el Yo, el viajero se lanza siempre hacia adelante; no se lleva a sí mismo, completamente, en su proceder, sino cada vez aniquila toda su identidad precedente y se lanza, se vuelve verdaderamente otro, con otros valores y sentimientos; otro que no logra reconocer su propio rostro. "Il chez tout", escribía Breton en 1922, exhortando a salir de viaje, invitando al dépaysement. El Ulysses (1922) de Joyce es quizá el último epos clásico, conservador, más conservador que la Odisea homérica; al final de su jornada, Leopold Bloom regresa a casa y confirma sus propios valores y sentimientos, desde el amor conyugal hasta el sentido de la familia y el deseo del hijo; valores y sentimientos que ciertamente esa jornada ha profanado, ridiculizado, manchado, pero no ciertamente apagado en su corazón. Él regresa a sí mismo, se afirma a sí mismo. No es Nadie; es más bien Cualquiera.

Cierto, la Odisea es el poema de la ausencia, pero también de 
la astucia que busca defenderse trasformando esta ausencia en una ventaja, haciendo de la carencia un anima para sobrevivir. El Ulises homérico es maestro en dar jaque al jaque, como sucede con las sirenas; es maestro de un arte absolutamente contemporáneo como aquel de ponerse a buen recaudo ya cubierto de todo riesgo. Ulises ya es el burgués que no arriesga, que estipula un seguro all risks; Ulises que se pone en la condición de no correr el riesgo de ser víctima de las sirenas es ya el sveviano Zeno que no arriesga con Ada, que elude la posibilidad de fracasar verdaderamente en su amor con ella.

Como dirá Adorno, Ulises domina destruyéndose y contemporáneamente destruye dominándose. Es el héroe de la ratio iluminista que vence y aniquila el poder del mito: después de su viaje de regreso no habrán más Cíclopes ni sirenas; las fuerzas arcanas de los estados primordiales serán destronadas y esfumadas. Ulises posee "una capacidad rara en el mundo homérico: el autocontrol." Pero el autocontrol es puro cálculo, astucia, dominio de sí por razones de oportunidad y por tanto dominio de los demás, Ulises que regresa solo a Itaca, único superviviente de su grupo, es la figura del sobrevivir en virtud de la potencia y del sacrificio de los demás, según la interpretación de Elías Canetti. La Odisea ya es además el poema de la impersonalidad, de la pérdida de la irreducible originalidad de la experiencia, Cuando, en la corte de los Feacios, el aedo Demodoco canta las gestas de Ulises - episodio que impresionaba en particular a Racine - Ulises, que las escucha junto con los demás, llora; llora porque se da cuenta que ya no le pertenecen más, no son más suyas, se han convertido en una especie de serie televisiva, diríamos hoy. Cuando, como en el espléndido Odiseo y Penélope de Mario Vargas Llosa (2006), Ulises cuenta sus gestas a Penélope, la odisea es suya, su vida narrada a su mujer; cuando las repiten, variándolas y adaptándolas los demás, ella no le pertenece más, es la expropiación de su vida. El yo vive su expropiación, su alienación. En El Desprecio (1954) de Moravia la Odisea se vuelve el guión cinematográfico de un film homónimo; 
operación de reescritura al cubo del mito, su refuncionalización en otro contexto, en otra técnica, ulterior pérdida del aura mítica. Ulises es el héroe mítico que destruye el mito con el iluminismo, según la célebre interpretación de Adorno y Horkheimer. La Odisea narra el último encuentro con el mito y disuelve este último con la crítica iluminista; desde este punto de vista, ya el Ulises homérico es un héroe moderno y progresivo, que se pone en presencia del mito con actitud iluminista. Cuando Circe trata de seducirlo y se da cuenta que no lo logra, como en cambio lo había logrado con sus demás compañeros, le dice: "Está en ti una mente que no se deja hechizar. Claro, tú eres Odiseo.” Hay un cuento de Lion Feuchtwanger, Odysseus und die Schweine (Odiseo y los puercos, 1950), en el que, cumplidas y terminadas las gestas de Ulises con su regreso victorioso a Itaca a la masacre de los Proci, el aedo Femio - perdonado, diversamente de los otros colaboracionistas de los Proci quizá menos culpables que él, como las doncellas, porque es necesario en cuanto voz ensalzadora, mediática, de la gloria de Ulises - exalta la victoria y el número de los caídos muertos. Pero sobre este número - dilatado en el énfasis de la gloria, reducido en una versión más realista, aumentado nuevamente para no menoscabar demasiado esa gloria - se pelea y se discute, como hoy sobre el número de las víctimas de Hitler o de Stalin, hasta que se llega aun acuerdo por un número convencional y es finalmente aceptado, mucho más amplio del real pero inferior al de las celebraciones más exaltadas: ni 39 ni 200, sino 118.

Y a propósito del episodio de Ulises que vuelve a transformar en hombres a los cerdos, en los que Circe los había transformado, hay uno que no quiere regresar a la vida humana, a su dignidad pero también a su sufrimiento, a todo lo que lo aparta del feliz abandono animal al seno de la naturaleza. Querría seguir siendo cerdo, un animal, naturaleza.

Hay tantos Ulises, en la literatura universal, después de Homero. Ulises en sí es una figura ambigua, alejada de la imagen tradicional, clásica de los otros grandes héroes. Se finge loco en el intento de no 
ir a la guerra de Troya, engaña a Ajax en el legado de las armas de Aquiles, engaña a Filoctetes. En la Iliada no está entre los héroes que sobresalen. Sobre todo para la tradición romana es una figura negativa, aquel que abandona o sacrifica a las mujeres. En la épica medieval es a menudo astuto y vil y Dante lo coloca entre los consejeros fraudulentos, aunque elevándole un canto que es probablemente la cúspide de toda la Comedia y de la literatura universal.

En el Trojius and Cressida (1602) de Shakespeare, Ulises es hábil persuasor, incluso intrigante pero sabio, consciente de la vanidad del tiempo, pero - también o quizá sobre todo por esto - de la necesidad de la jerarquía y del orden social. Goza de una imagen más positiva entre los Estoicos, como imagen de firmeza, que más tarde algunos lo verán como un símbolo de la constancia cristiana y de la búsqueda de la salvación, por ejemplo en la obra de Du Bellay en el siglo XVI, o de De Régnier en el siglo XIX. En otras naciones conoce otros rostros, se vuelve un poco el Simbad árabe, el escandinavo Egill o el irlandés Mailduin, todos grandes navegantes y ligados también a esa dimensión de la mentira que la tradición asocia a menudo al mar. En la obra de Alvaro Cunqueiro, el escritor gallego, Ulises se convierte en S. Ulises, inventor del remo y sobre todo del deseo de regresar apenas había partido, deseo de regreso que es nostalgia y, cada vez nueva creación del mundo.

En la Nausikaa de Goethe (1787) él es semiculpable, en cuanto es incapaz de decir toda la verdad a la bella doncella que ya, como él se da cuenta, lo ama; lo hace también por ambigua benevolencia paterna, en esa relación erótica sublimada en ternura paterna que se instaura entre él y la doncella mucho más joven. También en la obra de Giraudoux, La guerre de Troje n'aura pas lieu (La guerra de Troya no se hará, 1935), Ulises es el héroe de la política, que modernamente se ha vuelto el destino, un destino de guerra que estalla por un incidente, dado que en la edad contemporánea la férrea necesidad del destino ha cedido el lugar a la arbitrariedad caprichosa e insignificante del azar. La gran interrogante sobre el destino de Ulises concierne a su regreso y/o a su ulterior partida. Ya la tradición antigua conoce el no 
regreso, la partida que Tiresias le profetiza después de su regreso a Itaca y que él, además, ya anuncia de alguna manera a Penélope después del dichoso retorno al amor. No es necesario recordar el disparatado vuelo de Dante, Ulises que perece en lejanías ignotas, bajo cielos australes.

Los modernos y los contemporáneos, aparte el clásico y conservador Joyce, retoman sobre todo el tema del no-retorno, de la imposibilidad para Ulises de permanecer en Itaca después de su regreso. Así en el Ulysses de Tennyson (1842) Ulises es incapaz de permanecer "rey indolente al calor de mi hogar tranquilo": no puede prescindir de su errar, quiere beber la vida "hasta la amargura" y no puede apartarse del viaje. Deja a Telémaco la isla y el cetro; deja a él, al hijo - que debería ser el hombre del mañana respecto al padre, hombre de la tradición - el cultivar las "tiernas costumbres", el "dar el conveniente culto a los dioses de nuestra familia"; con los viejos compañeros se vuelve a poner de viaje hacia el consabido naufragio.

Pero Tennyson, en 1833, había escrito The lotos eaters (Los devoradores de loto), En este espléndido poema no se desea la heroica aventura, sino se desea el olvido, el apagado, dulce y cautivador hundirse en un velado crepúsculo que une a la naturaleza, Los marineros encuentran dulce soñar con la madre patria en la playa, pero ese sueño y ese olvido son para ellos más gratos que el verdadero retorno.

Estos Ulises aman una música dulce y suave, piden consuelo a la amapola, en un espíritu decididamente anti-faustiano, anti-ulisiaco en el sentido tradicional del término: “.,.pero ¿por qué debería ser la vida sólo congoja?” para ellos es dulce escuchar con ojos cerrados, semidormidos, el murmullo del agua y mirar los arabescos de la arena y los curvos arrequives de la espuma. El canto de esa gesta se vuelve "un relato insensato"; prefieren posar los miembros sobre lechos de asfódelos: "es mucho más dulce dormir en la playa/ de la fatiga al remo/ tregua, hermanos nautas, no vagaremos más”.

Aún más radical, en esta dirección, es Pascoli, en los Poemas conviviales (1904). En el sueño de Odíseo, Itaca escapa de Ulises que está por regresar allí pero no se da cuenta de ello, cogido por el sueño; 
el regreso se desvanece en un abandono, dulce y mortal. En el estupendo Últímo viaje, el regreso es negado por otra partida, que a su vez es un retorno: el viejo Ulises, muchos años después de haber regresado a Itaca, parte de nuevo para volver a ver los lugares de su odisea, de su valor, del significado de su vida. Pero no encuentra más nada, sólo un vago eco de lo que ha sido su vida, y comienza a dudar que haya sido realmente su vida. En el lugar de Polifemo, hay una especie de volcán apagado y antiguos recuerdos que hablan de fabulosos gigantes; las sirenas son dos escollos entre los cuales la nave se desintegra. Queda sólo Calipso, la escondida, la oceánica perdición amorosa similar a la muerte.

El último viaje es una de las más radicales expresiones poéticas de esa identificación del viajar con la muerte o al menos de esa relación entre el viaje y la muerte que Baudelaire o Gadda conocen muy bien. La nostalgia del Ulises pascoliano va a algo más remoto y antiguo que la odisea; a un momento embrionario, que precede a toda determinación; a una condición de infancia o más bien prenatal, a un regazo en el que se puede ser feliz porque la vida no existe aún, porque todo es aún germinal y posible y no conoce por tanto la desmentida ni la derrota. Incluso el amor existe, paradójicamente, sólo cuando no existe aún: "cantar el amor que dormía en el corazón,/ y que despertado sólo entonces en ti muere”. El amor existe sólo hasta que no existe aún; cuando es sueño, mera potencialidad. La odisea, en la gran poesía de Pascoli es el canto de la regresión. D’Annunzio celebra en cambio la dimensión heroica de Ulises, "la infatigable fuerza del magnánimo corazón” y el arco grande del "Rey de Tempestades", que el poeta invoca esperando saber tender también él su gran arco (Maya, 1903). Pocos años más tarde, en 1911, Gozzano transforma al rey de tempestades en "un tal/ que dio con el vivir sencillo/ un muy deplorable ejemplo/ de infidelidad marital,/ que vivió a bordo de un yate/ tocando entre dichosas brigadas/las playas más frecuentadas/ por las famosas cocottes/ [...] pero ni dulzura de hijo,/ ni lágrimas, ni la piedad del padre, ni el debido amor/ por su dulce mitad/ le apagaron dentro el ardor/ de la esperanza quimérica/ 
y volvió con tardos compañeros/ buscando fortuna en América.../ No se puede vivir $\sin /$ dinero, mucho dinero.../ considerad, mis queridos/ compañeros, vuestro linaje!".

Homero y Dante son ironizados y parodiados, en la conciencia epigonal tanto que a los modernos y a los contemporáneos ya no es más lícita ni posible la gran poesía heroica, sino solamente su parodia. Parodia que - como dice la etimología de la palabra, canto a latere - pone en relieve la pequeñez no ya del original inalcanzable, sino de quien, como los modernos y como el poeta mismo en este caso, no puede menos que rehacerle el verso. A él no le es lícita la odisea, sino sólo una caricatura suya: "entonces, entre una risa confundida, (con paz de Homero y de Dante)/ diríamos la fábula para la consorte ignorante." Aún más radical en esta senda de la "desheroización" está el Capitán Ulises de Alberto Savinio (1925) que es pirandellianamente también un teatro en el teatro. El autor imagina que hace visitar a Ulises el escenario en el que se recitará su historia, los entretelones y el taller de reparaciones y de repuestos para el espectáculo; a menudo dos espectadores interfieren en la representación y el primero consolará a Circe cuando ésta, abandonada por Ulises, saldrá desesperada de escena. Ulises aparece vestido de capitán de marina como un personaje de Jules Verne, los apuntes de Savinio para el vestuario prevén, por ejemplo, a Calipso en bata o tea-gown, Telémaco en eton-jacket negro, pantalones blancos de tela o de franela, corbata negra o a rayas.

Ulises se resiste a ser encasillado para siempre en el rol, fijado por el mito, del héroe del último viaje, sabiendo luego que éste siempre es el penúltimo, como el último cigarrillo de Zeno. Al final, en efecto, Ulises dejará que los demás partan para el último viaje o crean que él ha partido para el último viaje. Y en cambio va a cenar con el espectador. Pero este ballet grotesco -y humanísimo- está invadido por un profundo, aunque apenas aludido dolor, por la pérdida de sí y del sentido mismo, de la meta del retorno, de Penélope, pensada por años y transformada, en el momento del retorno, dolorosamente en otra: "una intrusa, usurpadora" que ha matado a la Penélope 
existente sólo en la mente de Ulises.

Obviamente en la poesía, también en la poesía contemporánea, existen muchas pausas y en las Mediterranée (1946) Saba en cambio puede reencontrar, en la figura de Ulises, una grandeza clásica imperecedera, "de la vida el doloroso amor", "el no domado espíritu” que empuja al poeta mar adentro, y así Pound reencontrará, en su aventura linguiística extremadamente innovadora, la grandeza arcaica y perenne del Ulises homérico que desciende al Averno. En la poesía Ithake (1894-1911) Kavafis escribe que Ulises no encontrará ni Lestrigones, ni Cíclopes ni al tempestuoso Poseidón si no los lleva consigo dentro de su alma, si su alma no los erige delante de él. "Itaca te ha dado el viaje maravilloso./ Sin ella no habrías partido./ Ahora no le ha quedado nada que darte”. Es ilusorio y culpable haber dejado Itaca reputándola mísera, incapaz de ofrecer nuevas aventuras y experiencias. Esta es la culpa de Ulises, no haber entendido que a la odisea se le puede, se le debe quizá encontrar y vivir en Itaca, en la cotidianidad.

Además de Kavafis, también Seferis y Kazantzakis han retomado el mito de Ulises; en la obra de este último (Odisseia, 1938), un marinero vagabundo, que termina en los océanos más lejanos, se busca a sí mismo porque también él es ya una parte de lo que ha encontrado en el viaje de su vida. El poeta lituano Sigitas Pasulskis hace hablar, sobre la tumba de Ulises, al hijo Telémaco, que le reprocha haber olvidado en la euforia de sus victorias que en la vida hay que "aprender no a vencer sino a perder, a sucumbir"; le reprocha la dureza de haber construido su existencia y su gloria como una fortaleza, en la cual él, su hijo, penetra como un caballo de Troya para destruirla. Musil no ha escrito una Odisea, pero su Hombre sin cualidades (1930, $1933 \neg 1978$ ), y sobre todo la parte incompleta y los borradores y capítulos definidos como "el viaje al Paraíso" (o sea la consecución de la perfecta unión amorosa en una zona mística que raya en la locura) son la odísea más radicalmente contemporánea, antihomérica y antijoyceana, porque narran el más radical de los no-regresos, aquel en el cual el yo se pierde a sí mismo, se convierte en otro. 
Esta fusión y tensión ulisíaca se desarrolla teniendo como fondo el horizonte de un gran mar abierto, de un infinito inexorablemente abierto, un infinito de mar y de cielo detrás del cual no hay nada, nada más que rayos de sol que danzan entre el agua y las piedras.

En esa playa suspendida más allá de la realidad, el infinito se presenta a los dos amantes como una abertura hacia la nada, como el ilimitado jirón de una abertura que se parece a una herida y disuelve cada identidad, cada odisea que es siempre una constitución de la identidad. El sujeto, el Yo se forma separándose de la naturaleza.

El itinerario musiliano es un nomadismo sin fin y sin regreso que va al extremo, el yo se vuelve continuamente otro por sí solo, se arroja y se proyecta hacia adelante, mutando su fisonomía y su naturaleza. La aventura del personaje musiliano no es circular, no es el regreso del espíritu a sí mismo, la confirmación de la identidad - de su unidad y de su continuidad - a través de la experiencia. No es un nostos, una odisea; es una trayectoria rectilínea que se lanza al infinito, que no regresa nunca a sí misma.

Si los personajes errabundos de Novalis van, incluso sin saberlo, "siempre hacia casa", los de Musil nunca pueden regresar a casa, también porque ni siquiera han partido de ella, están carentes e ignaros desde el principio. Viven una mutación, irreconocibles y ajenos incluso a sí mismos. Su identidad se dispersa, su unidad y continuidad se interrumpen. En este sentido El hombre sin cualidades el más grande libro de nuestro presente, un libro que quizá podemos leer recién hoy, porque nos dice nuestra incierta verdad actual: "todo nuestro ser [...] no es más que un delirio de muchos" y "la más profunda asociación del hombre con sus similares es la disociación”. "Estación meteorológica para el fin del mundo", como la llamaba Karl Kraus, la civilización habsburguesa, de la que Musil es el más grande intérprete, ha sido un laboratorio del nihilismo y de una irónica resistencia a ello.

De este paisaje, Trieste, que a inicios del siglo XX Hermann Bahr definía un "ningún lugar", era uno de los rostros más representativos. "Haz lo que quieras, pero no vayas de vacaciones a 
Austria”, así dice una postal expedida por Joyce a su hermano Stanislao y así inicia una novela polifónica y plural, que hace de Trieste el ombligo torcido del mundo y se intitula Absolut Homer. Absolut Homer, Homero absoluto, apareció, en alemán, en 1995. Como autor, se podría señalar a Walter Grond, germanista y narrador austriaco. Los autores sin embargo, coordinados por él, son 22 , procedentes sobre todo de Alemania y de Austria, pero también de Francia, Hungría o de Japón. El libro nació como un trabajo colectivo y con un ambicioso proyecto: reescribir una vez más aún la Odisea, con la conciencia de reescribir la obra por excelencia de los orígenes, del primer mítico autor que inauguró la tradición de la creatividad poética y el mito del poeta, pero de reescribirla en la época en que la obra literaria individual, el mismo yo individual y aún más el poeta están terminando o ya terminaron, desaparecidos, absorbidos en la red superpersonal de la escritura, en un flujo comunicativo en el que la individualidad se pierde como una gota en el mar o una imagen en el espejo.

Ya Homero se planteaba como nombre ficticio: quizá hombre quizá mujer (como sostiene Samuel Butler en el volumen The Authoress of the Odissey (La autora de la odisea, 1897); quizá uno quizá muchos; quizá - según otros personaje de la historia que cuenta. Homero es el símbolo del Autor que, en cuanto individuo y creador preciso, no existe, sino es un puro nombre, una convención, una sigla. También los poemas homéricos son como los cantos balcánicos acompañados con la gusla, o como los amautas o los Quipucamayoc incas, quizá originariamente el producto de un equipo. Por otro lado la épica es de por sí superindividual, una totalidad coral en la que el individuo se inserta y en la que todo se mantiene orgánicamente junto, gracias al sentido de la unidad que lo embarga, Este carácter épico es por otro lado fruto también de una moderna proyección nostálgica. Desde los orígenes basilares - que a la sensibilidad epigonal y decadente de los siglos y milenios sucesivos parecen una auroral e incorrupta pureza espontánea -la poesía es eco de otras poesías, voz que entona cantos flui- 
dos de otros labios; el poeta, el aedo que pronuncia el "fiat" de la creación, realiza ya un "remake", Cuando Homero punteaba la lira, dice una poesía de Kipling, tomaba lo que quería de donde quería. Homero, escribe Grond, es inicio y fin de la identidad y ya tiene validez para él la interrogante que acucia al escritor moderno y postmoderno: ¿quién narra? Historias generan otras historias, una fluctuante memoria colectiva emerge a la conciencia individual y la sumerge; la literatura trata de cubrir y de domesticar el horror originario de la vida, pero contemporáneamente no puede prescindir de desencadenarlo, desgarrándose a sí misma ya su propia ordenada textura. Siguiendo la tesis de la antropóloga vienesa Christine Pellech, según la cual la Odisea evocaría una circunnavegación fenicia del globo, el libro dilata la geografía homérica mucho más allá del Mediterráneo, yendo hasta las Lofoti, hasta Sudamérica o los Mares del Sur. Felice Vinci, un ingeniero nuclear apasionado de fantasiosas y minuciosas verificaciones geográfico-linguiísticas, ha sustentado, "Ios orígenes nórdicos de la Odisea y de la Iliada”, en localidades y en tradiciones míticas escandinavas o finesas los paisajes de Circe o de Calipso. El epicentro continuamente presente en el Homero de Grond, la Itaca de esta odisea, es Trieste; su topografía es el mapa de una travesía del mundo en la mente, Y en Trieste, ciudad de papel e inventada por excelencia, reside "el secretario", que debería ser el presunto Autor de la novela, aquel que recoge los diferentes cuentos de veintidós escritores, como un sitio de Internet, o, si se quiere, como la tradición (¿pre?) homérica acogía a los diferentes cantos, fragmentos y episodios que confluían en ella.

Laobrapodríaformarsecomountextodigital,compuestopormuchos interlocutores que colaboran a distancia. El autor es "transindividual", sunombre esuna merasigla, podríallamarseNadie comoUlises, Google. En los Hombres claros (1974), el escritor triestino Renzo Rosso vuelve a narrar el capítulo final de la historia de Ulises, extrayendo de ella lo que ya Hornero había intuido, pero que nadie había captado con tanta fuerza o sea el inicio de una despiadada parábola histórica que lleva la civilización a crecer destruyendo la pequeña, insignificante 
pero tierna vida acostumbrada, arrastrando a la humanidad a una espiral de violencia, de dominio, de genial grandeza y cruel eficiencia, de potencia metafísica y técnica; una espiral que exalta, celebra, trastorna al mundo y al hombre mismo, marcando el destino de Occidente y, al fin y al cabo, del mundo.

A grandes resultados llega esa potente épica, esa trágica odisea contemporánea, excesiva y desmesurada como el mar, que es Horcynus Orca de Stefano D’Arrigo (1975). Épica ulisiaca, marina: el mar es símbolo mismo de la totalidad, con el ritmo de su respiración, de su unidad infinitamente variada, la Vida que engulle las vidas y las regenera como el romperse y renacer de las olas. En las densísimas mil trescientas páginas de la novela, que mezcla Odisea, Moby Dick y Joyce, D’Arrigo narra la historia del marinero Ndrja Cambria que, después del colapso de Italia en 1943, trata de regresar a casa, a Caribdis, atravesando, en la total decadencia política y social del País, las costas calabresas, hasta morir casi en el umbral del imposible retorno.

Este viaje lo conduce no sólo al infierno de la historia, sino también y sobre todo a aquellos de la vida misma y de la muerte, del sueño, del eros, del miedo. El mar es el fondo y a la vez el lenguaje de este gran Eros indistinto, dador de vida y de muerte. Con una invención linguiística excepcional, D’Arrigo parece hacer hablar al mar, el coro de sus innumerables voces, su carácter épico total. La Orca, el monstruo de los abismos al final muerto y devorado por las "feere" en memorables páginas, es la misma proliferación de la vida y por ende de la muerte, que tanto más ésta provoca tanto más es poderosa. D’Arrigo se inventa un lenguaje de por sí inexistente pero vivo en la sugestión del léxico y de inflexiones dialectales de la costa tirrénica, desde Campania hasta Calabria y Sicilia, recuperando el leitmotiv de la Odisea, el viaje de regreso a casa. La épica vuelve a recorrer, en el marco de la Italia devastada de 1943, las etapas de Ulises: Circe, los Cíclopes, los Lestrigones, los Lotófagos y todos los demás episodios de un itinerario que debería ser de salvación, pero se vuelve un aprendizaje para la muerte. Odisea degradada, prolife- 
rante y tumoral, pero grandiosa.

Absolut Homer dilataba el viaje ulisiaco a los océanos más inconmensurables, el poema Omeros de Derek Walcott (1990) lo transfiere al mar del Caribe, cuenca como el Mediterráneo - de una mezcolanza, de una "creolización” que funde numerosas civilizaciones (inglesa, francesa, española y holandesa de los colonizadores, india de los habitantes originarios, africana de los descendientes de esclavos, indostánica, siria, y china de los inmigrados). La tradición se hace realmente universal, tanto europea como africana, indostánica o caribeña; en la isla de Santa Lucía, en el Caribe, la gente (pescadores, taxistas) tiene nombres homéricos y clásicos como en un tiempo los esclavos. Aquiles y Héctor son rivales por el amor de Elena, mientras Siete Mares, el ciego vidente, recuerda ya sea a Tiresias como a Filoctetes con la piema purulenta.

El cantor Homero se confunde, al trasmitir la tradición, con los antiguos cantores africanos presentes en la memoria ancestral de los nietos de esclavos, así como Aquiles, por otra parte desclasado a taxista, se confunde con el antepasado africano Afolabo, los dioses olímpicos se mezclan con los dioses africanos, el patois local se fusiona con lengua alta de los colonizadores. El mito de Ulises se renueva continuamente; la Odisea, dice Alberto Manguel, siempre es rescrita. Margaret Atwood retoma la historia, pero contándola desde el punto de vista de Penélope: The Penelopiad: The Myth of Penelope and Odysseus (El canto de Penélope. El mito del retomo de Odiseo, 2005). Como ya sucede en el texto homérico, también en aquel de la Atwood él es un "tejedor de engaños", un mentiroso, al que también se puede creer de vez en cuando; aunque su relación conyugal con Penélope es falsa y a la vez verdadera. El Cíclope es un hospedero, las diosas son mujerzuelas y Penélope misma es infiel; esta parece la realidad verdadera, de la que no obstante - es siempre Penélope quien lo dice -se posesionan los cantores, retocándolas y obteniendo versiones elegantes, en las que Odiseo regresa inteligente, valiente, ingenioso, comprometido en la lucha contra monstruos sobrenaturales y predilecto de las diosas. Si aún no ha 
efectuado el regreso a casa, no es porque se haya abandonado a alguna aventura trufaldina, como es probable, sino porque, dice el canto, contra él se han puesto Poseidón, señor del mar, o incluso el Hado. Pero sobre todo Penélope se confronta con un paso terrible de la conclusión de la Odisea o bien el ahorcamiento de las doncellas. ¿Por qué esta ejecución de las doncellas? Quizá porque son cómplices, colaboracionistas de los Proci, durante la larga ausencia de su señor - pero entonces, ipor qué perdonar la vida a Femio, el cantor, el intelectual, cuyo compromiso es aún más grave? ¿Quizá porque el intelectual se recicla fácilmente en cada régimen, por cuanto resulta útil? ¿O más bien porque las doncellas son custodios de secretos (tal vez relacionados con el comportamiento de Penélope) que el mito, la versión oficial, no puede tolerar? Odiseo verdugo de las doncellas se muestra bajo una luz terrible y a las doncellas moribundas les queda una única retorsión: dirigirse a las diosas de la Venganza, a las Furias, para que hagan justicia y la única justicia que ellas podrán tener será la prosecución del mito; serán las variantes que mostrarán también aspectos deshonrosos o indecorosos del héroe, que lo harán mostrarse bajo una luz no heroica, que lo harán expiar la culpa de ese su regreso. "iOh diosas de la venganza, Oh Furias, Os imploramos infligir en nuestro nombre la pena y la justa venganza! iDesanidad a Odiseo, dondequiera que vaya! De un lugar a otro, de una vida a otra, con cualquier disfraz que vista, con cualquier aspecto que asuma, acorraladlo, dondequiera que pueda encontrar refugio, en la canciones y en las tragedias, en los tomos o en las discusiones! Trasformaos en nosotros y presentaros ante él de improviso, con nuestro cuerpo aniquilado, que inspira piedad. iNo le deis tregua!".

Conozco demasiado poco la literatura peruana y en general la hispanoamericana para decir si también ella tiene sus Ulises; ciertamente tiene sus errantes viajeros que atraviesan los altiplanos, las montañas Andinas, como Ernesto en Los ríos profundos (1958) de José María Arguedas, en un errar que no sé si es fuga o retorno. La novela El síndrome de Ulises (2006) del colombiano Santiago 
Gamboa narra con violencia "la odisea de un expatriado latinoamericano", ha escrito Carlos Fuentes. A este Ulises exiliado en París el retorno no le está vetado por razones políticas o familiares; no está vetado por nada, sino por la "exigencia devoradora" del viaje y de la aventura, por la necesidad interior de no retornar antes de haber experimentado todas las posibilidades y las modalidades de exilio o sea de no retornar nunca. Ya Timothy Findley, en su novela Famous last words (Las últimas palabras famosas, 1981), había rememorado la segunda guerra mundial sobre el modelo mitológico de la Iliada; la guerra entre democracia y fascismo o también entre ingleses y alemanes o entre clases hegemónicas y clases subalternas es también una guerra entre Griegos y Troyanos. Aquiles es un nazista que en lugar del talón vulnerable tiene zapatos de cocodrilo y el Homero narrador está dispuesto a colaborar o a participar en un complot bajo el nombre en código "Penélope". Alguien ha visto una Odisea también en la novela Zone (2009) de Mathias Énard, una novela que consiste en una única frase larga como quinientas diecisiete páginas, un flujo ininterrumpido como el del mar, que cuenta la historia de Francis Servain Mirkovic, franco-croata, exvoluntario en las guerras de la ex Yugoslavia, agente de los servicios secretos franceses, investigador de bibliotecas y archivos, que viaja en una noche en el tren nocturno Milán-Roma con su valija. Ésta contiene la documentación preciosa de todo lo que él ha reunido; contiene la Historia que Francis querría vender a caro precio a alguien interesado en tener esas cartas, en esconderlas, en usarlas, en falsificarlas. Francis, "Ulises moderno" que desciende en su propio lado oscuro, desde la juventud fascista fascinada por la violencia hasta el alcoholismo y las experiencias de guerra en Argelia, que retornan continuamente con pesadillas espantosas de muerte y de masacre.

El mito se hace casi adaptable a placer, en una de suya peligrosa extensión que puede hacer o querer hacer parecer cada historia como una odisea, borrando su especificidad. No obstante tan grandes resultados poéticos, una sombra de cansancio epigonal se 
extiende sobre las recuperaciones del mito. Probablemente, en la vida cual odisea, Homero ya había dicho todo y sus tantas reelaboraciones, también fascinantes, extraen su fascinación de ese inagotable original. Por ello éstas retornan y varían esas reposiciones y esas variaciones. Walcott mismo, en una poesía, ha celebrado la lectura "que antepone el amor por las obras maestras al intento de repetirlas y superarlas” (Volcano. Volcán.). Esa muerte que, según el mito mismo, debería venirle a Ulises del mar, cerrando definitivamente la historia podría, a este punto, presentarse como una liberación. 